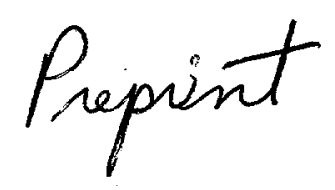

\title{
Subcritical Crack Growth in Ceramic Composites at High Temperature Measured Using Digital Image Correlation
}

Daniel R. Mumm, Winfred L. Morris, Mahyar S. Dadkhah and Brian N. Cox

Rockwell Science Center, Thousand Oaks, CA

November, 1996

To appear in : "Thermal and Mechanical Test Methods and Behavior of Continuous-Fiber Ceramic Composites," ASTM STP 1309, Micheal G. Jenkins, Stephen T. Gonczy, Edgar Lara-Curzio, Noel E. Ashbaugh, and Larry P. Zawada, Eds., American Society for Testing and Materials, 1996 
Daniel R. Mumm, ${ }^{1}$ Winfred L. Morris, ${ }^{2}$ Mahyar S. Dadkhah, ${ }^{2}$ and Brian N. Cox ${ }^{2}$

\section{SUBCRITICAL CRACK GROWTH IN CERAMIC COMPOSITES AT HIGH TEMPERATURE MEASURED USING DIGITAL IMAGE CORRELATION}

REFERENCE: Mumm, D. R., Morris, W. L., Dadkhah, M. S., and Cox, B. N., "Subcritical Crack Growth in Ceramic Composites at High Temperature Measured Using Digital Image Correlation," Thermal and Mechanical Test Methods and Behavior of Continuous-Fiber Ceramic Composites, ASTM STP 1309, Michael G. Jenkins, Stephen T. Gonczy, Edgar Lara-Curzio, Noel E. Ashbaugh, and Larry P. Zawada, Eds., American Society for Testing and Materials, 1996.

ABSTRACT: An in situ experimental technique is described that allows high resolution, high sensitivity determination of displacements and full-field strains during high temperature mechanical testing. The technique is used to investigate elevated temperature crack growth in $\mathrm{SiC} / \mathrm{Nicalon} \mathrm{f}_{\mathrm{f}}$ composites. At $1150^{\circ} \mathrm{C}$, the reinforcing fibers have a higher creep susceptibility than the matrix. Fiber creep leads to relaxation of crack bridging tractions, resulting in subcritical crack growth. Differential image analysis is used to measure the crack opening displacement profile $u(x)$ of an advancing, bridged crack. With appropriate modeling, such data can be used to determine the traction law, from which the mechanics of cracking and failure may be determined.

KEYWORDS: crack growth, bridging, differential image correlation, creep, composites

Fiber reinforcement has been demonstrated to be an effective means of toughening intrinsically brittle materials, such as ceramics and intermetallics. A principal source of the improved toughness is crack bridging by fibers left intact in the wake of an advancing crack $[1,2]$. If crack bridging is the primary toughening mechanism, the force/displacement behavior of the bridging fibers determines the crack shielding. The mechanics of cracking and failure can be determined fully provided the magnitude and distribution of the crack bridging tractions are known [3]. When the bridging zone is large relative to the size and spacing of the bridging elements, the discrete tractions may be approximated as a continuous closure pressure acting on the crack faces. Numerous models have been devel-

${ }^{1}$ Member of Technical Staff, Structural Ceramics Department, Rockwell Science Center, 1049 Camino Dos Rios, Thousand Oaks, CA 91360.

2 Members of Technical Staff and Manager, respectively, Design \& Reliability Department, Rockwell Science Center, 1049 Camino Dos Rios, Thousand Oaks, CA 91360. 


\section{DISCLAIMER}

This report was prepared as an account of work sponsored by an agency of the United States Government. Neither the United States Government nor any agency thereof, nor any of their employees, make any warranty, express or implied, or assumes any legal liabiity or responsibility for the accuracy, completeness, or usefulness of any information, apparatus, product, or process disclosed, or represents that its use would not infringe privately owned rights. Reference herein to any specific commercial product, process, or service by trade name, trademark, manufacturer, or otherwise does not necessarily constitute or imply its endorsement, recommendation, or favoring by the United States Government or any agency thereof. The views and opinions of authors expressed herein do not necessar. ily state or reflect those of the United States Government or any agency thereof. 


\section{DISCLAIMER}

Portions of this document may be illegible electronic image products. Images are produced from the best available original document. 
oped expressing the crack bridging tractions as a function, $p(u)$, of the crack opening displacement, $u(x)$, at a position, $x$, in the crack wake. Cox and Marshall [3] have developed a method for deducing the function $p(u)$ from experimental measurements of the crack opening profile $u(x)$ of a single crack. For an assessment of both the functional form and quantitative validity of bridged crack models for brittle-matrix composites, precise crack opening profile measurements are needed. However, few such measurements have been reported.

Analysis of bridging tractions from crack opening profiles requires an accuracy in displacement measurements of $\sim 1 \%$ of the opening at the notch root or the crack mouth [3]. For a composite such as $\mathrm{Al}_{2} \mathrm{O}_{3} / \mathrm{SiC}_{\mathrm{w}}$, loaded to the critical applied stress intensity, the maximum opening of a crack of length $100 \mu \mathrm{m}$ may be on the order of $1 \mu \mathrm{m}$. The required measurement accuracy is then $\sim 10 \mathrm{~nm}$. This is beyond the limits of conventional techniques for strain and displacement measurement, but within the capabilities of stereoscopy [4,5] or related automated displacement mapping techniques [6,7] based upon differential image analysis. The present article addresses the need for critical measurements of crack opening profiles during mechanical testing of ceramic composites by describing an experimental technique that allows quantitative measurement of crack opening displacement profiles for bridged cracks in brittle-matrix composites.

At high temperatures, crack-bridging tractions may be affected by one or more of the following: (1) creep of the composite constituents, (2) viscous deformation of interphase layers, grain boundary phases or matrices with glassy phases, (3) relief of residual stresses resulting from thermal expansion mismatch, and (4) environmental attack, for example, oxidation of the fiber-matrix interface. Although modelling must account for the temperature and time dependence of the crack opening profile, understanding the mechanics of crack growth and failure remains a question of determining the crack bridging tractions from measurements of $u(x)$.

The purpose of this work is to develop a high temperature test system that is capable of providing optical images of suitable quality for differential image correlation and thence to provide $u(x)$ data of sufficient resolution for use with bridged-crack models accounting for temperature-dependent and time-dependent crack growth in CMCs. The test system described in this work is used to investigate an important damage mechanism for high temperature ceramic composites, where crack growth occurs owing to a systematic degradation of bridging tractions with creep relaxation of crack bridging fibers.

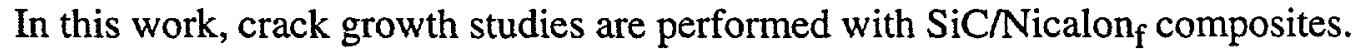
Analysis of images acquired at $1150^{\circ} \mathrm{C}$ show that multiple cracking occurs upon monotonic loading. However, with constant applied load, stable growth of a single dominant crack is observed, with propagation to failure. Degradation of the bridging tractions is characterized by measuring crack opening displacement profiles as a function of time. Although the materials studied are woven composites, the measured bridging zones are large relative to the size and spacing of the crack bridging elements. Therefore, the crack bridging tractions can be considered as a continuous closure pressure, and the measured profiles provide data for bridging parameter evaluation using models such as those cited above.

Cracking and damage can be significantly affected by oxidation occurring at the fiber/matrix interface. Studies of these effects are beyond the scope of this paper, and all testing reported here is done in an argon atmosphere to avoid interfacial degradation. 


\section{STRAIN MEASUREMENTS VIA DIFFERENTIAL IMAGE CORRELATION}

Image Acquisition and Analysis

Strain measurement using differential image analysis requires high quality images of the specimen surface contrast during various stages of a test procedure. Sensitive measurements of surface strains are made through comparison of a pair of optical micrographs, one taken before a change in the material takes place (the reference) and the other taken after. For example, a pair of micrographs may be taken before and after specimen loading, or the micrographs may be from different times of a constant load creep experiment. Strains or crack openings are measured by determining the relative changes in position of surface contrast features. The relative displacements may be measured by comparing pairs of micrographs using a stereoviewer, in which in-plane displacements are perceived as changes in height [4,5]. Stereoimaging takes advantage of the exceptional sensitivity of the human visual system to small changes in apparent depth $[4,5]$. A crack appears as a sharp ledge viewed from above. Quantitative displacement measurements are made by comparison of the perceived surface profile with a calibrated travelling spot [8]. Since the observed features are essentially unchanged from one image to the next, other than in precise position, the accuracy of measurement exceeds the point-to-point resolution of the microscope used to record the images [6]. Relative displacements of $\pm 5 \mu \mathrm{m}$ can be determined on high quality optical micrographs. This corresponds to a displacement sensitivity of $\sim 100 \mathrm{~nm}$ on micrographs of only $50 \times$ magnification, that is, over a field of view of $\sim 2 \mathrm{~mm}$ on the sample.

Manual methods of differential image analysis (stereoscopy) suffer from being tedious; considerable time can be spent analyzing displacements or strains from a single pair of micrographs. Furthermore, only the displacements parallel to the axis of the stereoviewer are measured. To obtain the orthogonal component of the relative displacement required for accurate determination of shear strains, both micrographs must be rotated exactly $90^{\circ}$, and the displacements must be measured from precisely the same reference position. Such limitations can be alleviated by automating the differential image analysis through digital image processing techniques $[6,7]$ making use of cross-correlation procedures. In addition to improving the speed at which measurements may be obtained, automated image correlation is a powerful technique for determination of shear strains, as both components of the in-plane displacement are measured simultaneously. In this work, manual stereoscopic image analysis is used, as displacements are sought only in one direction, and only a small number of measurements are made per pair of micrographs.

\section{Specimen Preparation}

The strain measurement technique relies on imaging contrast that occurs on the surface of the specimen. A specimen surface with a dense, random distribution of highly contrasting features is ideal. In many cases, sufficient contrast exists naturally on the specimen surface. Material inhomogeneity or the microstructure can provide useful contrast. A highly polished sample is not always optimal. For instance, with the composites discussed in the following part of this paper, a highly polished surface shows large, matrix-rich regions with no contrast. Strain measurements cannot be obtained from such regions. In other materials, the scale of the microstructure or other natural features 
providing contrast is too fine (or, possibly too coarse) to provide useful contrast at the desired magnification. In such cases, intentional contamination, surface decoration, or even fine scratching of the specimen surface can be introduced. For accurate strain measurement during high temperature testing, the features providing contrast must be thermally stable. The specimen surface must be flat (relative to the depth of field of the viewing instrument at the given magnification) so that the area over which measurements are to be made is in focus, and stays in focus with deformation of the specimen.

\section{EXPERIMENTAL APPARATUS}

The apparatus developed for quantitative investigation of high temperature crack growth has four independent systems to allow: (1) acquisition of high resolution images; (2) precise control of loading, deformation, and fracture; (3) accurate temperature control; and (4) atmosphere control. The system is built around a standard benchtop-sized servohydraulic test frame with associated electronics (servo-controller and signal conditioners). Images are acquired using an optical microscope attached to a high-stiffness, three-axis positioning system. To control vibrations transmitted from the surroundings, the loading system and optical microscope are rigidly fixed to a common plate and attached to a large mass sitting on pneumatic isolators. A means of securing the camera assembly was devised so that inserting and removing polaroid film does not disturb positioning or focal conditions, while still allowing fine adjustments of the microscope for initial focussing.

The specimen is heated with a compact, custom-built furnace with a flat Kanthal heating element designed to allow viewing of the specimen while minimizing thermal gradients. The furnace includes a quartz window which is partially mirrored to reflect much of the radiant energy. Sample temperature is determined with attached thermocouples. The loading system includes water-cooled grips. The optical microscope incorporates a custom coaxial light source with a fiber-optic cable and high intensity xenon lamp. The resulting intense illumination overpowers the thermal radiation of the sample, providing high quality images with consistent contrast, regardless of temperature. The current system includes an enclosure so that testing may be done in air or with a slight overpressure of inert gas, although there are no technical barriers to more elaborate atmosphere control. The ability to control the test environment can be a significant advantage over in situ techniques making use of a scanning electron microscope, in which all testing is done in vacuum, because high temperature failure mechanisms involving environmental degradation may be directly investigated.

In examining potential sources of error, the magnification uniformity for this system has been analyzed over the available magnification range of 6.3 to $32 \times$. Analysis of control micrographs, in which the only change made is the position of the imaging system, shows that with positioning errors as large as $100 \mu \mathrm{m}$ (relative to the sample surface), errors in the measured strains are well below the measurement resolution.

\section{HIGH TEMPERATURE CRACK GROWTH IN SiC/NICALON COMPOSITES $_{\mathrm{f}}$}

At high temperature, brittle matrix composites are subject to a variety of cracking and damage modes, some depending on the relative creep susceptibilities of the fiber and 
matrix [9,10]. In many ceramic composites, fine-grained fibers exhibit creep behavior while the matrix remains elastic at service temperatures. Such materials are susceptible to crack growth at high temperature owing to an interactive process involving fiber creep and matrix cracking. Creep relaxation of bridging fibers leads to crack propagation as the shielding effect is reduced and stress transfer to the matrix occurs. With crack propagation, new fibers are brought into the bridging zone and fiber stresses increase, advancing creep relaxation effects [11]. Materials exhibiting this behavior include $\mathrm{SiC} / \mathrm{Nicalon}_{\mathrm{f}}$ composites such as those used in this work.

Experimental work reported by Henager and Jones [12] showed that under constant load conditions, steady-state cracking is observed with SiC/Nicalon composites $_{\mathrm{f}}$ at $1100^{\circ} \mathrm{C}$. The reported crack growth rates were calculated on the basis of compliance change, assuming all changes were entirely due to crack growth. However, compliance changes continuously with relaxation of bridging tractions even in the absence of crack propagation. The in situ technique described above is used to investigate time-dependent crack growth in $\mathrm{SiC} / \mathrm{Nicalon}_{\mathrm{f}}$ composites at $1150^{\circ} \mathrm{C}$. The technique allows direct measurement of crack length and crack opening displacement profiles, so that changes may be directly correlated with test parameters: the load, temperature, and time.

\section{Materials and Specimen Preparation}

Nicalon reinforced CVI $\beta$-SiC composites (E.I. Dupont de Nemours \& Co., Inc., Wilmington, $\mathrm{DE}$ ), with reinforcement in the form of plain weave $0 / 90^{\circ}$ cloth layers, were tested. The reinforcements have a carbon-rich coating, providing a weak interface in the composite. The as-supplied eight-ply composites were approximately $3.5 \mathrm{~mm}$ thick. Compact-tension (CT) specimens were machined from a 200 - by $200-\mathrm{mm}$ plate in accordance with ASTM Test Method for Measurement of Fatigue Crack Growth Rates (E 647), with specimen dimensions of $W=31.75 \mathrm{~mm}$ and $B=3.00 \mathrm{~mm}$. The specimens were notched to a depth of $13.40 \mathrm{~mm}\left(a_{o} W=0.42\right)$, with a half chevron notch present $2.24 \mathrm{~mm}$ farther into the material. A Knoop indent (5 kg applied load) was placed at the tip of the chevron notched region to facilitate further the initiation of a sharp crack. The sample surfaces were ground flat to a $25-\mu \mathrm{m}$ finish. Additional specimen polishing was not done, as it reduces the density of contrast features useful for image correlation.

A pertinent review of the available creep data for CVD SiC and Nicalon fibers is given by El-Azab and Ghoniem [13]. Using data reported by Gulden and Driscoll [14], who measured the creep characteristics of CVD SiC, and the results of DiCarlo and Morscher [15], who measured creep strains for Nicalon fibers over the temperature range $1000^{\circ} \mathrm{C}$ to $1500^{\circ} \mathrm{C}$, the relative creep rates of the composite constituents are compared. At a temperature of $1150^{\circ} \mathrm{C}$, the creep rate of Nicalon fibers is more than five orders of magnitude greater than that of CVD SiC. Therefore, in this work, creep effects are considered only for the bridging.fibers.

\section{Test Procedures}

Specimens were precracked at room temperature by fatigue loading at $5 \mathrm{~Hz}$, at a stress intensity range of $\Delta K=10.6 \mathrm{MPa} \cdot \mathrm{m}^{1 / 2}$ and an $R$ ratio of 0.1 . Sharp cracks initiated at the tip of the Knoop indent, growing approximately half the distance to the end of the chevron notch. The samples were unloaded before heating to the test temperature of 
$1150^{\circ} \mathrm{C}$. Precracking and testing were done in a flowing argon atmosphere to minimize environmental effects (interfacial oxidation). Examination of the fracture surfaces after failure (Fig. 1) shows substantial fiber pullout and no evidence of fiber/matrix interface degradation (i.e. $\mathrm{SiO}_{2}$ formation).

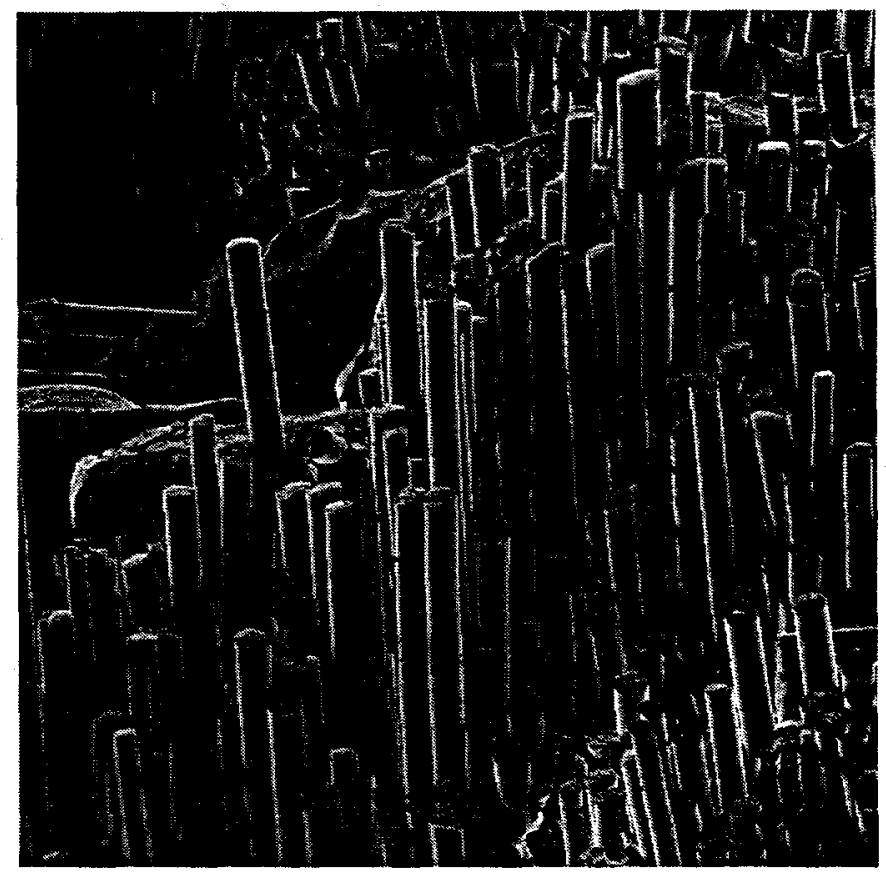

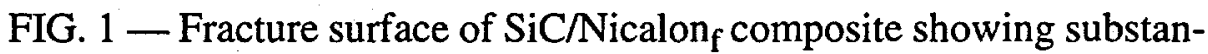
tial fiber pullout and no evidence of interfacial oxidation following subcritical crack growth to failure at $1150^{\circ} \mathrm{C}$.

Observations and measurements made during testing of a single specimen are as follows. The specimen was held at an applied stress intensity of $0.1 \mathrm{MPa} \cdot \mathrm{m}^{1 / 2}$ while heating to $1150^{\circ} \mathrm{C}$. After stabilizing at the desired test temperature, reference micrographs were obtained before the load was increased monotonically. Loading was interrupted at 350 and $700 \mathrm{~N}$ for image acquisition. The load was held at $700 \mathrm{~N}$ to acquire images over $\sim 200 \mathrm{~min}$. The specimen was then loaded to $800 \mathrm{~N}$ and held for over $110 \mathrm{~h}$, until failure occurred with creep crack growth. All optical images were obtained at $30 \times$ magnification.

\section{RESULTS AND DISCUSSION}

The ability to map displacements with high precision allowed detection of damage that would not have been observable by direct imaging. An example is shown in Fig. 2. With monotonic loading to $350 \mathrm{~N}$ (less than half the maximum precracking load, $K_{\text {app }}$ $\sim 5.0 \mathrm{MPa} \cdot \mathrm{m}^{1 / 2}$ ), partial opening of the fatigue precrack was observed (see Fig. $1 a$ ). Continued loading, above the precracking load, to $800 \mathrm{~N}\left(K_{\text {app }} \sim 13.3 \mathrm{MPa} \cdot \mathrm{m}^{1 / 2}\right)$ caused 
subcritical growth of the initial crack. Secondary cracks developed to the sides of the main crack, indicating the distributed nature of the damage occurring with monotonic loading (Fig. 2b). While holding at constant load, the main crack continued to open and extend, presumably because of creep relaxation of crack bridging fibers (Fig. $2 c, d$ ). It is important to note that (at this magnification), the secondary cracks, and significant portions of the main crack, could not be observed in individual micrographs as the resolution is insufficient. Even on high magnification images of highly polished specimens, cracks such as those indicated here are difficult to detect because they are often within the interfacial coating on fibers aligned with the crack growth direction. Such cracks were detected and measured only through differential image analysis, in which a crack appears as a discontinuity in the differential displacement of contrast features.

The orientations of surface ply fiber tows are indicated in Fig. $2 \mathrm{a}\left(0^{\circ}\right.$ tows are parallel to the loading axis). A pore resulting from incomplete infiltration during CVD

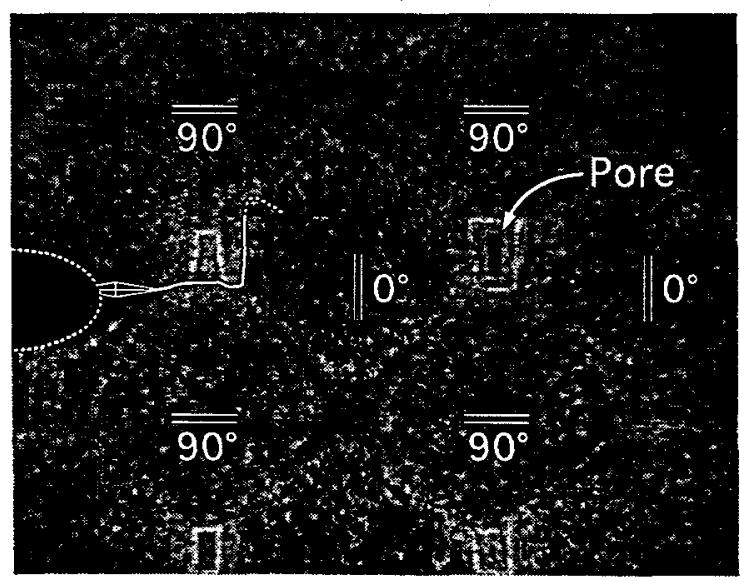

(a)

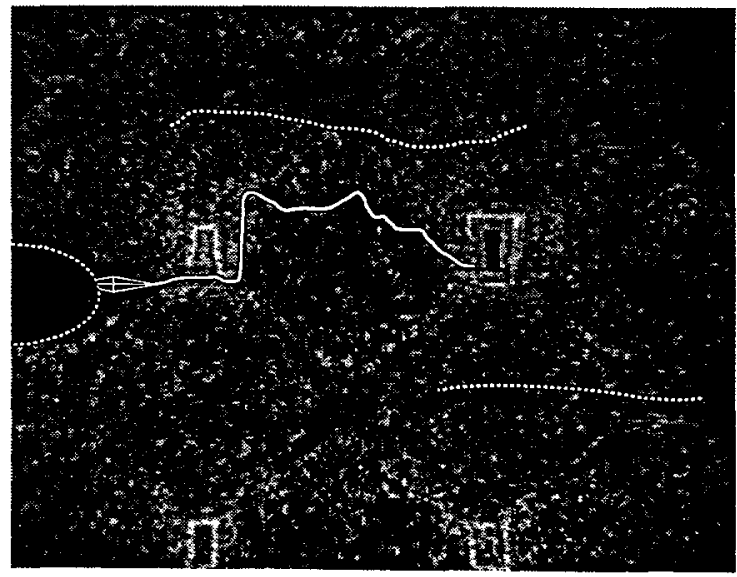

(c)

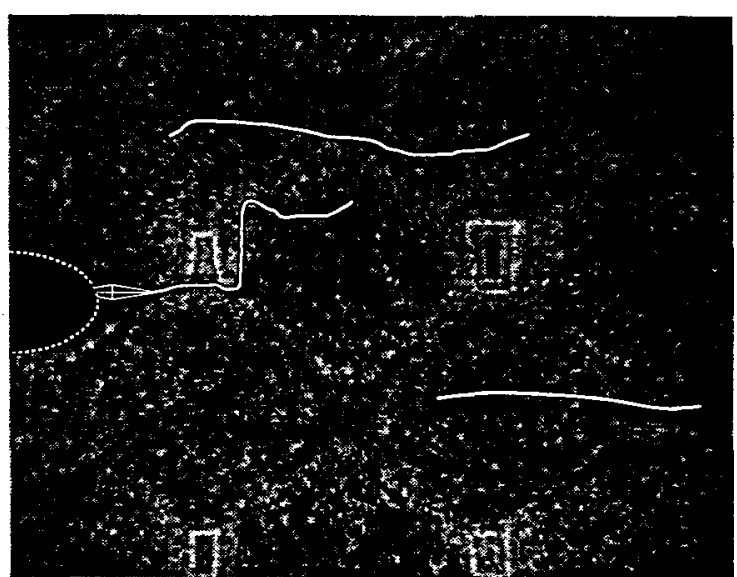

(b)

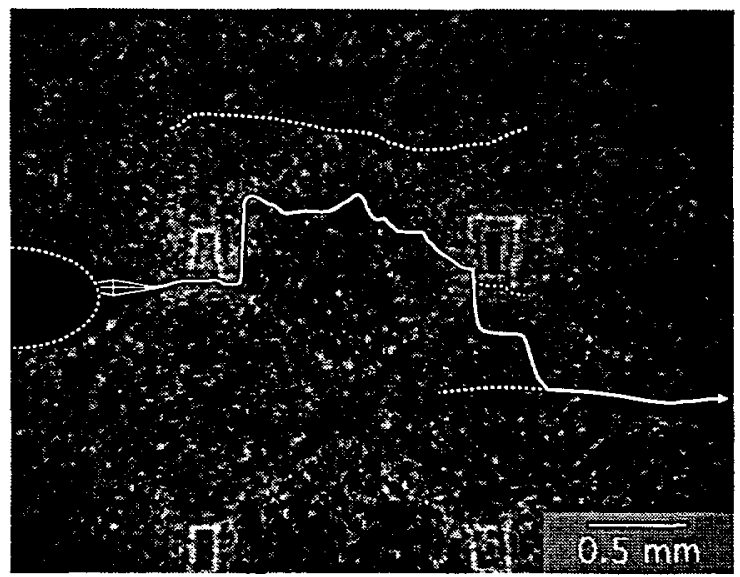

(d)

FIG. 2 - Evolution of damage with loading at $1150^{\circ} \mathrm{C}:(a)$ partial opening of the fatigue precrack at $350 \mathrm{~N},(b)$ crack extension and secondary cracking observed immediately upon loading to $800 \mathrm{~N}$, and after holding at constant load for $(c) 706 \mathrm{~min}$ and $(d) 4232 \mathrm{~min}$. Width of field $=3.61 \mathrm{~mm}$. 
processing is also noted. The precrack initiated within a matrix-rich region between tows and deflected at the edge of a $0^{\circ}$ tow. Secondary cracking during monotonic loading (Fig. 2b) occurred parallel to the fibers within $90^{\circ}$ tows. The main crack extended perpendicular to the $0^{\circ}$ fibers, eventually linking up with one of the secondary cracks. The crack paths appear to correlate with geometrical features of the fiber architecture visible in the surface ply. However, far-field deformations indicate that cracks illustrated in Fig. 2 are present as through-thickness features, rather than as surface cracks. Furthermore, although the overall $0^{\circ} 190^{\circ}$ orientation of fiber tows is maintained, the individual plies are randomly offset relative to one another, so that $0^{\circ}$ tows in one ply may be aligned with $0^{\circ}$ tows, $90^{\circ}$ tows, matrix-rich regions, or pores in other plies. A developing crack encounters microstructural features other than those noted on the specimen surface. Therefore, the overall crack growth is not correlated with any particular microstructural feature noted in the outermost ply of the composite.

Crack opening displacements measured at various points along the main and secondary cracks immediately following monotonic loading to $800 \mathrm{~N}$ are shown in Fig. 3 . The measured crack profiles are qualitatively consistent with expectations for bridged edge and center cracks. More importantly, the crack opening displacement at the notch root is more than double that measured anywhere along either of the side cracks. Stress in the bridging fibers is proportional to the local crack opening displacement, and the rate of creep will, therefore, be greater for bridging fibers at the notch root. Growth of the crack emanating from the notch root occurs while attendant changes in the secondary cracks are not observed.

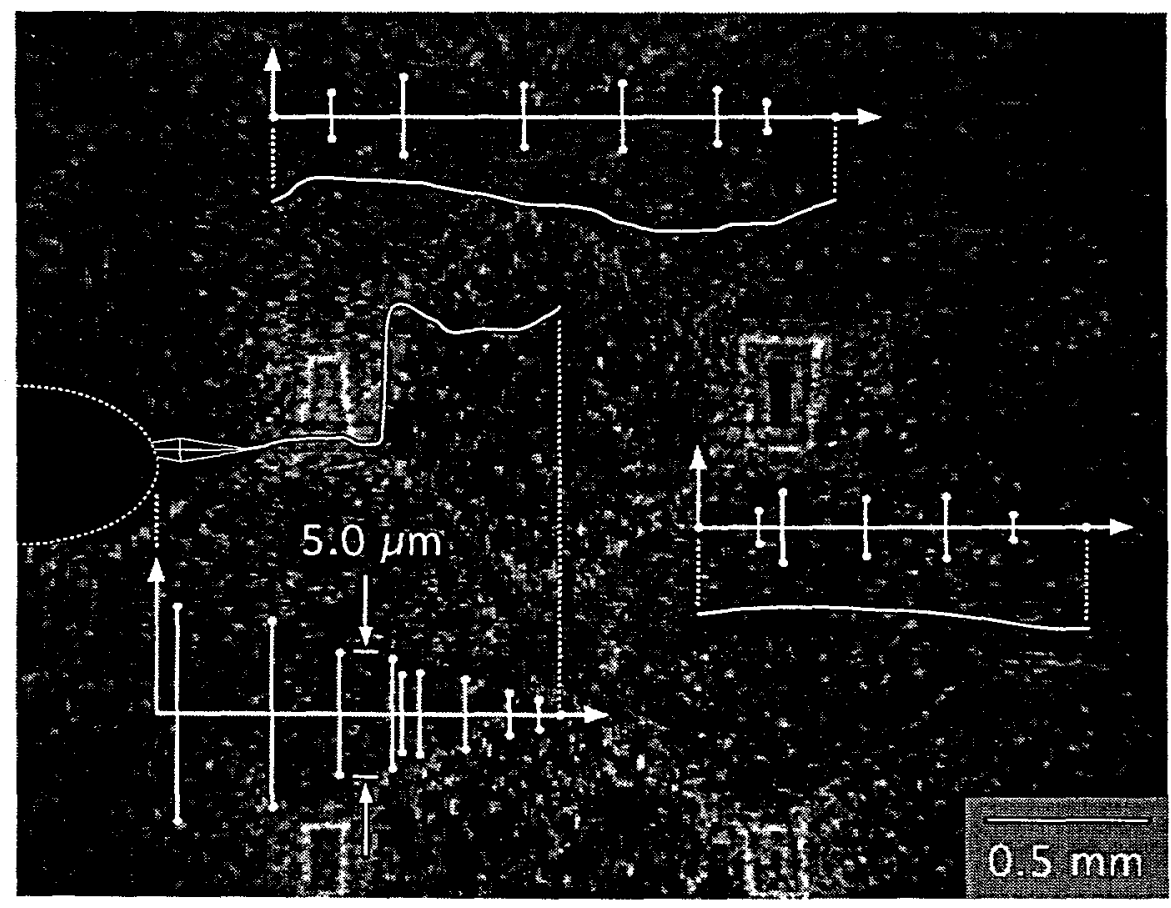

FIG. 3 - Crack opening displacements measured immediately after loading to $800 \mathrm{~N}$ at $1150^{\circ} \mathrm{C}$. Width of field $=3.61 \mathrm{~mm}$. 
To investigate the effects of fiber creep independently of crack growth, the initial loading of the specimen was interrupted at a level $(700 \mathrm{~N})$ just below that used for precracking. At this load, bridging fibers were likely to be stressed above the creep threshold, so that creep relaxation would occur while holding at constant load. Moreover, slight degradation of the bridging tractions could occur without attaining a critical condition for crack advance. Crack opening displacement profiles were determined from micrographs taken immediately after the loading interruption and after holding at constant load for $184 \mathrm{~min}$. The results are plotted in Fig. 4. Changes in the crack opening of $<0.5 \mu \mathrm{m}$ were resolved. Although the crack tip position remained unchanged over this time period, the crack opening increased with time, the largest changes occurring nearest the notch in which the bridging tractions were highest and the fibers were most susceptible to creep.

Similar measurements were made while holding at 800-N load. Changes in the crack opening displacement profile and the crack length were characterized over a period of $\sim 110 \mathrm{~h}$, at which point matrix crack propagation occurred unstably across the remainder of the specimen. The results are summarized in Fig. 5. The profile measurements show a continuously increasing crack opening displacement, again owing to stress relaxation in the bridging fibers. Crack growth occurred intermittently, presumably because of local variations in the crack resistance with material heterogeneity (matrix-rich regions and local variations in the fiber volume fraction). Measurements such as those plotted in

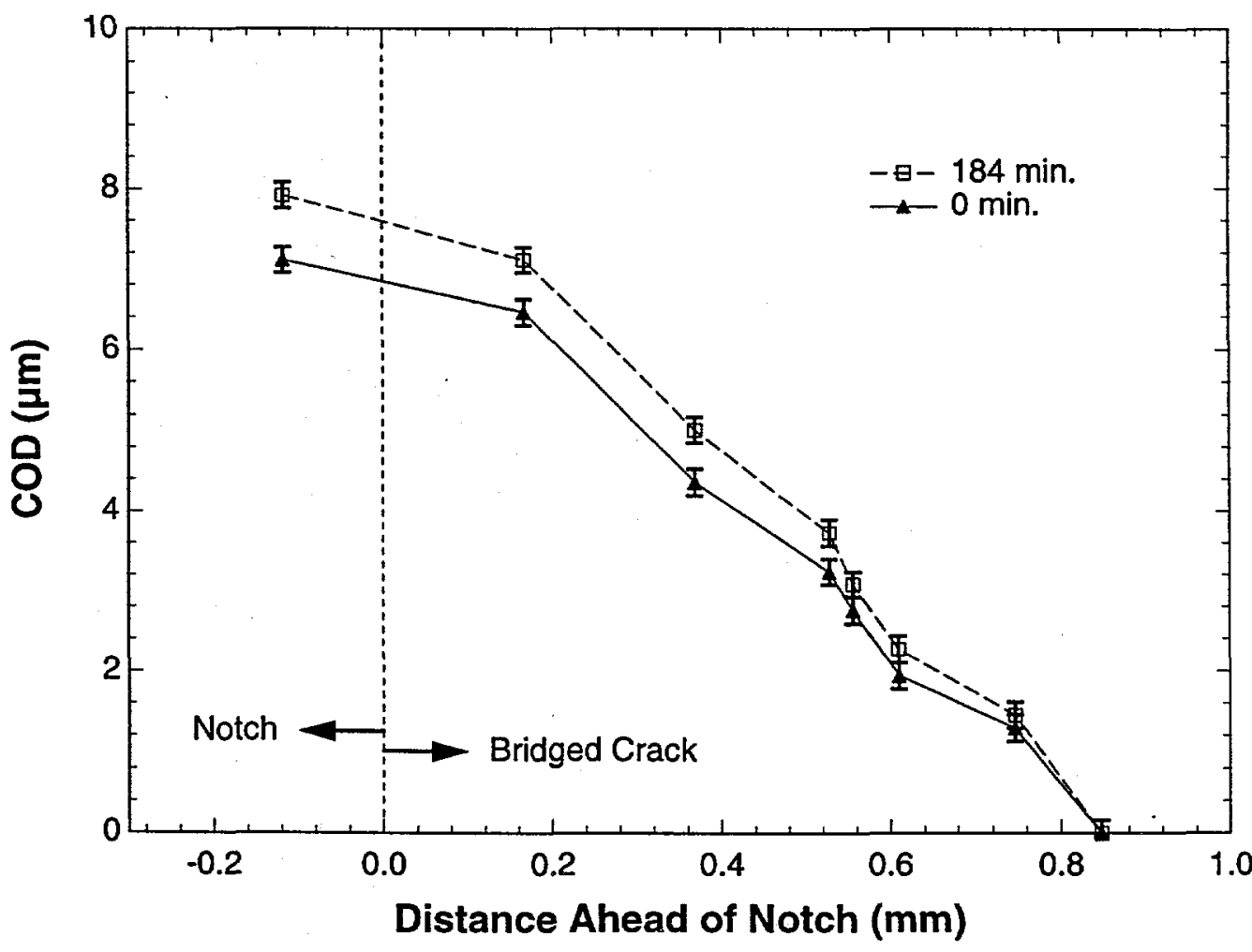

FIG. 4 - Evolution of the crack opening displacement profile with creep relaxation of bridging fibers, under constant load conditions at $700 \mathrm{~N}$. 


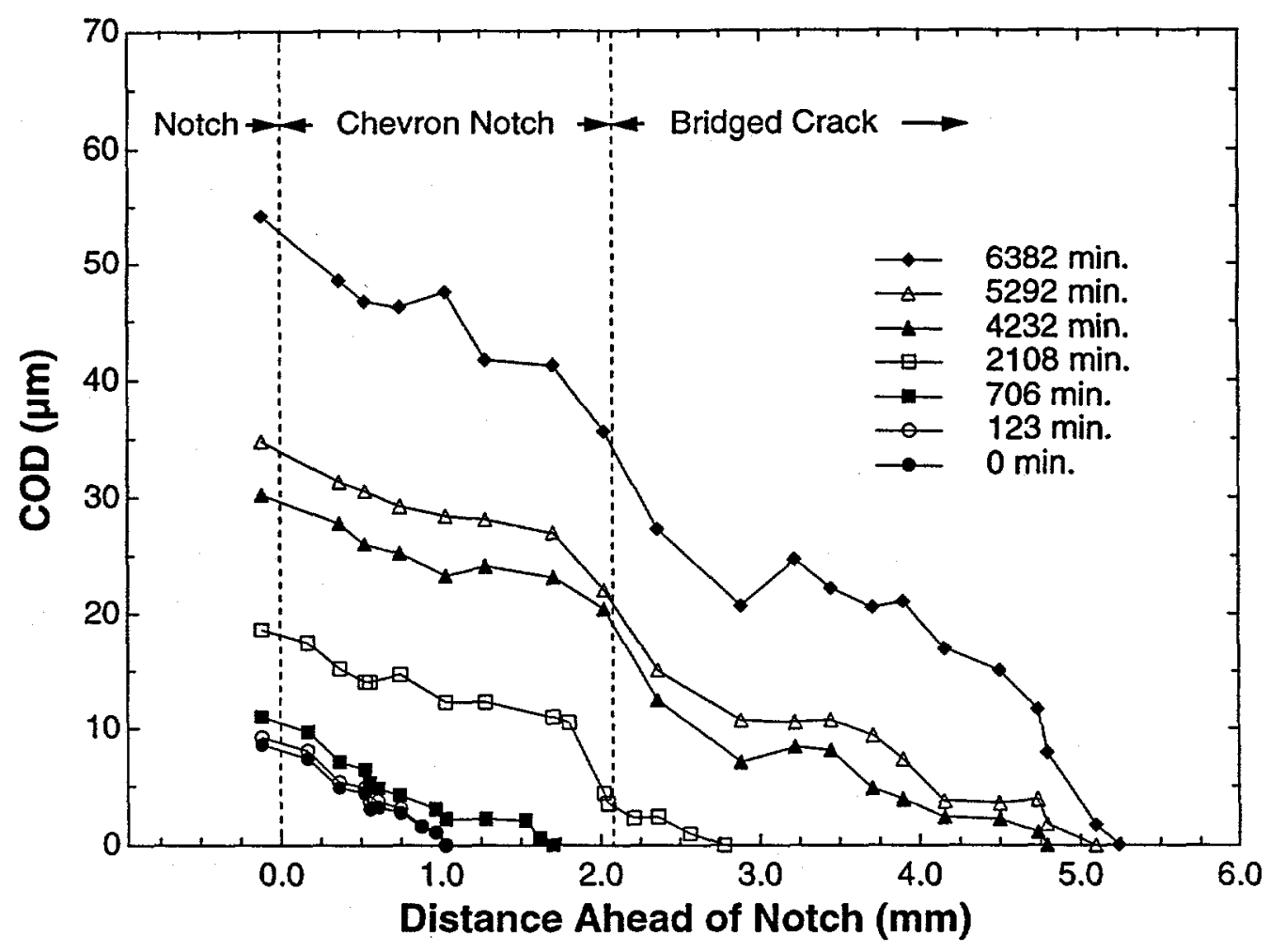

FIG. 5 - Evolution of the crack opening displacement profile with creep relaxation of bridging fibers, under constant load conditions at $800 \mathrm{~N}$. Relaxation of bridging stresses leads to subcritical crack propagation.

Fig. 5, obtained as a function of temperature and time, provide $u(x)$ data for direct comparison to theoretical predictions of crack growth at high temperature.

\section{CONCLUSIONS}

An in situ technique permitting high resolution, high sensitivity strain measurements during elevated temperature mechanical testing of brittle-matrix composites is discussed. The technique has general utility for investigation of damage and failure mechanisms for high temperature, high performance structural materials. The technique is applied to study crack growth in a ceramic composite at $1150^{\circ} \mathrm{C}$, in which the reinforcing fibers are subject to creep. Crack opening displacements are determined as a function of position behind the crack tip, providing data for a direct evaluation of the mechanics of crack bridging at high temperature. At constant applied load, crack growth can be correlated with degradation of the crack-bridging tractions, measured as an increased crack opening displacement along the length of the bridged crack. Such data can be used with appropriate models to determine the traction law during various stages of crack growth. The measurements and observations presented demonstrate the utility of this technique for investigation of high temperature crack growth and failure mechanisms for CMCs. 


\section{ACKNOWLEDGMENTS}

This work was funded mainly by the U.S. Department of Energy, Contract DEFG03-89ER45400. Funding by the U.S. Department of Energy does not constitute endorsement of the views expressed herein.

\section{REFERENCES}

[1] Aveston, J., Cooper, G. A., and Kelly, A., "Single and Multiple Fracture," in The Properties of Fiber Composites: National Physical Laboratory Conference Proceedings, IPC Science and Technology Press, Teddington, U.K., 1971, pp. 15-26.

[2] Marshall, D. B., and Evans, A. G., "Failure Mechanisms in Ceramic-Fibre/Ceramic-Matrix Composites," Journal of the American Ceramic Society, Vol. 68, No. 5, 1985, pp. 225-231.

[3] Cox, B. N., and Marshall, D. B., "The Determination of Crack Bridging Forces," International Journal of Fracture, Vol. 49, 1991, pp. 159-176.

[4] Davidson, D. L., "The Observation and Measurement of Displacements and Strain by Stereoimaging," Proceedings: Scanning Electron Microscopy 1979, Washington, D.C., April 1979, SEM, Inc., AMF O'Hare, IL, 1979, Vol. 2, pp. 79-86.

[5] Williams, D. R., Davidson, D. L., and Lankford, J., "Fatigue-Crack-Tip Plastic Strains by the Stereoimaging Technique," Experimental Mechanics, Vol. 20, 1980, pp. 134-139.

[6] James, M. R., Morris, W. L., and Cox, B. N., "A High Accuracy Automated Strain-field Mapper," Experimental Mechanics, Vol. 30, No. 1, 1990, pp. 60-67.

[7] Franke, E. A., Wenzel, D. J., and Davidson, D. L., "Measurement of Microdisplacements by Machine Vision Photogrammetry (DISMAP)," Review of Scientific Instruments, Vol. 62 No. 5, 1991, pp. 1270-1279.

[8] Cox, B. N., Morris, W. L., and James, M. R., "High Sensitivity, High Spatial Resolution Strain Measurements in Composites and Alloys," in Proceedings of the Nondestructive Testing and Evaluation of Advanced Materials and Processes Conference, Colorado Springs, $\mathrm{CO}, 1986$.

[9] Evans, A. G., and Zok, F. W., "The Physics and Mechanics of Fibre-Reinforced Brittle Matrix Composites," Journal of Materials Science, Vol. 29, 1994, pp. 3857-3896.

[10] McMeeking, R. M., "Models for the Creep of Ceramic Matrix Composites," in Elevated Temperature Mechanical Behavior of Ceramic Matrix Composites, S. V. Nair and K. Jakus, Eds., Butterworth-Heinemann, Stoneham, MA, 1994.

[11] Begley, M. R., Cox, B. N., and McMeeking, R. M., "Time Dependent Crack Growth in Ceramic Matrix Composites with Creeping Fibers," Acta Metallurgica et Materialia, Vol. 43, No. 11, 1995, pp. 3927-3936.

[12] Henager, C. H., and Jones, R. H., "High-Temperature Plasticity Effects in Bridged Cracks and Subcritical Crack Growth in Ceramic Composites," Materials Science and Engineering, Vol. A166, 1993, pp. 211-220.

[13] El-Azab, A., and Ghoniem, N. M., "Investigation of Incubation Time for Sub-Critical Crack Propagation in SiC-SiC Composites," Journal of Nuclear Materials, Vol. 219, 1995, pp. 101-109.

[14] Gulden, T. D., and Driscoll, C. F., "Creep of Chemically Vapor-Deposited B-SiC with an Analysis of Creep in Bending," Gulf General Atomic Report GA-10366, 1971.

[15] DiCarlo, J. A., and Morscher, G. N., "Creep and Stress Relaxation Modeling of Polycrystalline Ceramic Fibers," in Failure Mechanisms in High Temperature Composite Materials, G. K. Haritos, G. Newaz and S. Mall, Eds., ASME AD-Vol. 22, AMD-Vol. 122, 1991, p. 15. 